\title{
Two and a half minutes with the President
}

There are certain things that are not well taught at public health school. We focus on epidemiology and statistics until they are coming out of students' ears. Health economics, health services research, needs assessment and now health impact assessment have joined the toolkit along with a whole string of strategies, frameworks and concepts. The need for management expertise throughout health and healthcare systems has belatedly joined the emphasis on analysis and report writing on population health status; the recognition that when the epidemiology and situation analysis has been done, the real work is only just beginning. Yet it is unusual to prepare future practitioners for working under stress to short deadlines or "thinking on your feet", as Professor Jerry Morris at the London School of Hygiene and Tropical Medicine described it to our Masters class in 1976. Public health work is often serendipity in action, strategic opportunism and intuition harnessed to analysis-you can't do anything effectively if you don't know what needs to be done.

I will always be grateful to Ian Dillow, one of the National Health Service's first public relations experts, who taught me as a public health student in Wessex almost 25 years ago, how to handle the media- to have your two or at most three points clear in your mind and to get them in whatever the questions; something politicians seem to know from the mother's milk. At Liverpool we set one piece of course assessment as précis-no more than 1000 words; the students objected, said it was too difficult and later persuaded staff to raise the word limit to 1500 ! But nothing can prepare you for the heat of the real furnace, except experience and the adrenaline of the corridors of power and the moment. What do you say to your minister who wishes to be briefed on a difficult and controversial matter (teenage pregnancy) prior to a meeting with the prime minister on the subject, and your anticipated 30 minutes discussion over tea has become five minutes squashed between late running appointments? Or when suddenly, and out of the blue in the scorching heat of a Macedonian refugee camp, you manage to engineer the opportunity to bend the ear of the most powerful democratic leader in the world about the plight of the remaining priority medical cases in the camps when peace has been agreed, the humanitarian delegations are going home but there are still almost 1000 people in dire medical situations with little prospect of appropriate medical aid? ${ }^{1}$

Coming face to face with President Clinton, the "have you got a minute, I need to talk to you about the remaining priority medical cases in the camps?" being met by the totally unexpected "go on then, tell me about it", and you have about 2.5 minutes to tell the tale (fig 1). At that moment (in touch with emotion and intuition) and in real time it felt like Owen Meaney in John Irving's novel'; as if one's entire career to date had been in preparation for this moment-get it right and you can leverage out significant humanitarian assistance at a critical moment, get it wrong and hundreds of people's health and lives may be severely affected. In the novel, Owen Meaney had practised and practised the basketball manoeuvre that, because of his small physique, enabled him to be lifted to score the goal; when the basketball became a grenade in a crowded public space, he was able to
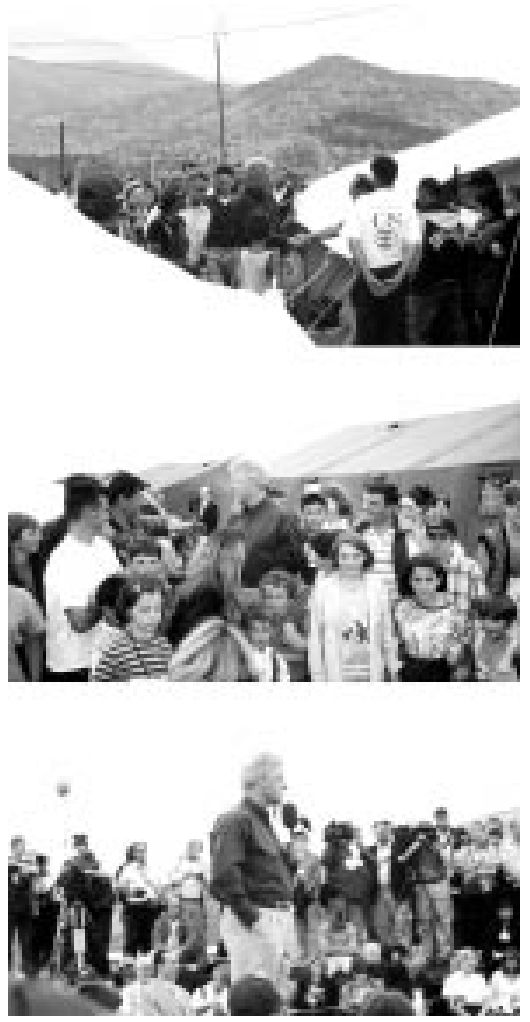
Figure 1 President Clinton visiting Stenkovec refugee camp in Macedonia shortly before an throw it out through a high-set window. It depended on teamwork and practise, practise coupled with instinct at the critical moment when my local translator, wedged in the crowd, sensed me behind him, eyes in the back of his head, and created a space for me to shake the President's hand and meet his eyes. On that day in Macedonia, and subsequently, I have thought many times of Owen Meaney.

JOHN R ASHTON, CBE (jech@liverpool.ac.uk)

1 Ashton J. Balkans briefing number 5. Seeking refuge (Macedonia, 9-25 June 1999): the changing needs of humanitarian aid in the face of the peace. $\mathcal{F}$ Epidemiol Community Health 2000;54:469-72.

2 Irving J. A prayer for Owen Meaney. London: Bloomsbury, 1989. 